\title{
Ambient noise cross-correlation observations of fundamental and higher-mode Rayleigh wave propagation governed by basement resonance
}

\author{
Martha K. Savage, ${ }^{1}$ Fan-Chi Lin, ${ }^{2}$ and John Townend ${ }^{1}$ \\ Received 9 May 2013; revised 14 June 2013; accepted 17 June 2013; published 19 July 2013.
}

[1] Measurement of basement seismic resonance frequencies can elucidate shallow velocity structure, an important factor in earthquake hazard estimation. Ambient noise cross correlation, which is well-suited to studying shallow earth structure, is commonly used to analyze fundamental-mode Rayleigh waves and, increasingly, Love waves. Here we show via multicomponent ambient noise cross correlation that the basement resonance frequency in the Canterbury region of New Zealand can be straightforwardly determined based on the horizontal to vertical amplitude ratio ( $\mathrm{H} / \mathrm{V}$ ratio) of the first higher-mode Rayleigh waves. At periods of 1-3 s, the first higher-mode is evident on the radial-radial cross-correlation functions but almost absent in the vertical-vertical cross-correlation functions, implying longitudinal motion and a high $\mathrm{H} / \mathrm{V}$ ratio. A one-dimensional regional velocity model incorporating a $1.5 \mathrm{~km}$-thick sedimentary layer fits both the observed H/V ratio and Rayleigh wave group velocity. Similar analysis may enable resonance characteristics of other sedimentary basins to be determined. Citation: Savage, M. K., F.-C. Lin, and J. Townend (2013), Ambient noise cross-correlation observations of fundamental and higher-mode Rayleigh wave propagation governed by basement resonance, Geophys. Res. Lett., 40, 3556-3561, doi:10.1002/grl.50678.

\section{Introduction}

[2] Understanding the near-surface seismic velocity structure of the Earth is important for assessing earthquake hazards. The uppermost few tens of meters are particularly important for determining the shaking expected during large earthquakes and for determining near-surface corrections for oil and mineral surveys. Cross correlation of long records of noise is now routinely used to determine Green's functions between pairs of seismic stations [e.g., Lin et al., 2008; Shapiro and Campillo, 2004]. Cross-correlation functions ("cross-correlograms") typically contain large-amplitude fundamental-mode Love and Rayleigh waves, and surface wave traveltimes based on these phases have now been

Additional supporting information may be found in the online version of this article.

${ }^{1}$ Institute of Geophysics, Victoria University of Wellington, Wellington, New Zealand.

${ }^{2}$ Seismological Laboratory, California Institute of Technology, Pasadena, California, USA.

Corresponding author: M. K. Savage, Institute of Geophysics, Victoria University of Wellington, Box 600, Wellington 6140, New Zealand. (martha.savage@vuw.ac.nz)

(C)2013. American Geophysical Union. All Rights Reserved. 0094-8276/13/10.1002/grl.50678 used to study seismic velocity structure at scales of $10 \mathrm{~m}$ (e.g., $S$ wave structure in the uppermost $30 \mathrm{~m}$ for seismic hazard assessment [e.g., Louie, 2001]) to $>10^{7} \mathrm{~m}$ (e.g., continental-scale crustal structure [Moschetti et al., 2010]).

[3] The ellipticity of Rayleigh wave particle motion, often expressed as the horizontal/vertical ("H/V") amplitude ratio, can in principle also be studied using noise cross correlation [Boore and Toksoz, 1969; Lin et al., 2012; Sabra et al., 2005] and provides independent constraints on geological structure. However, most noise cross-correlation studies use verticalcomponent seismograms only and focus solely on fundamental-mode Rayleigh waves. Traditional single-station $\mathrm{H} / \mathrm{V}$ noise spectral ratio analysis [Bonnefoy-Claudet et al., 2006; Fäh et al., 2001; Nakamura, 1989] is often used to determine the resonance response of sedimentary basins and other geological structures, despite the fact that the physical origin of the signal is somewhat ambiguous and dependent on the exact knowledge of the waves contained in the ambient noise signals (see review by Bonnefoy-Claudet et al.[2006]).

[4] Some noise cross-correlation studies have examined higher modes using beamforming [Behr et al., 2013; Brooks et al., 2009; Harmon et al., 2007; Kimman et al., 2012] and slant-stack analysis [Behr, 2011]. A recent analysis examined $\mathrm{H} / \mathrm{V}$ ratios in a geotechnical study of the uppermost few tens of meters, using linear arrays of geophones to record surface waves from noise and suggested that radial components could help to distinguish first-order and higher modes [Boaga et al., 2013] .

[5] We examine the nine components of cross correlations of records from an $80 \mathrm{~km}$-wide network of three-component seismometers on the Canterbury Plains, New Zealand (NZ). We observe fundamental mode surface waves and also pronounced higher-mode Rayleigh wave energy at 1-3 s period on the horizontal but not vertical components. We relate this to the basement resonance response of the onland portion of the Canterbury Basin.

\section{Data}

[6] Following the $M_{w} 7.1$ Darfield earthquake of 4 September 2010 [Gledhill et al., 2011; Quigley et al., 2010], we deployed four broadband and 10 intermediate-period seismometers within $50 \mathrm{~km}$ of the Greendale Fault; these instruments operated until mid-January 2011 (Figure 1). Details of the network and aftershock studies were reported by Syracuse et al. [2012], E. Syracuse et al. (High-resolution relocation of aftershocks of the Mw 7.1 Darfield, New Zealand, earthquake and implications for fault activity, submitted to Journal of Geophysical Research, 2013) and R. Holt et al. (Crustal stress and fault strength in the Canterbury Plains, New Zealand, submitted to Earth and Planetary Science Letters, 2013). 


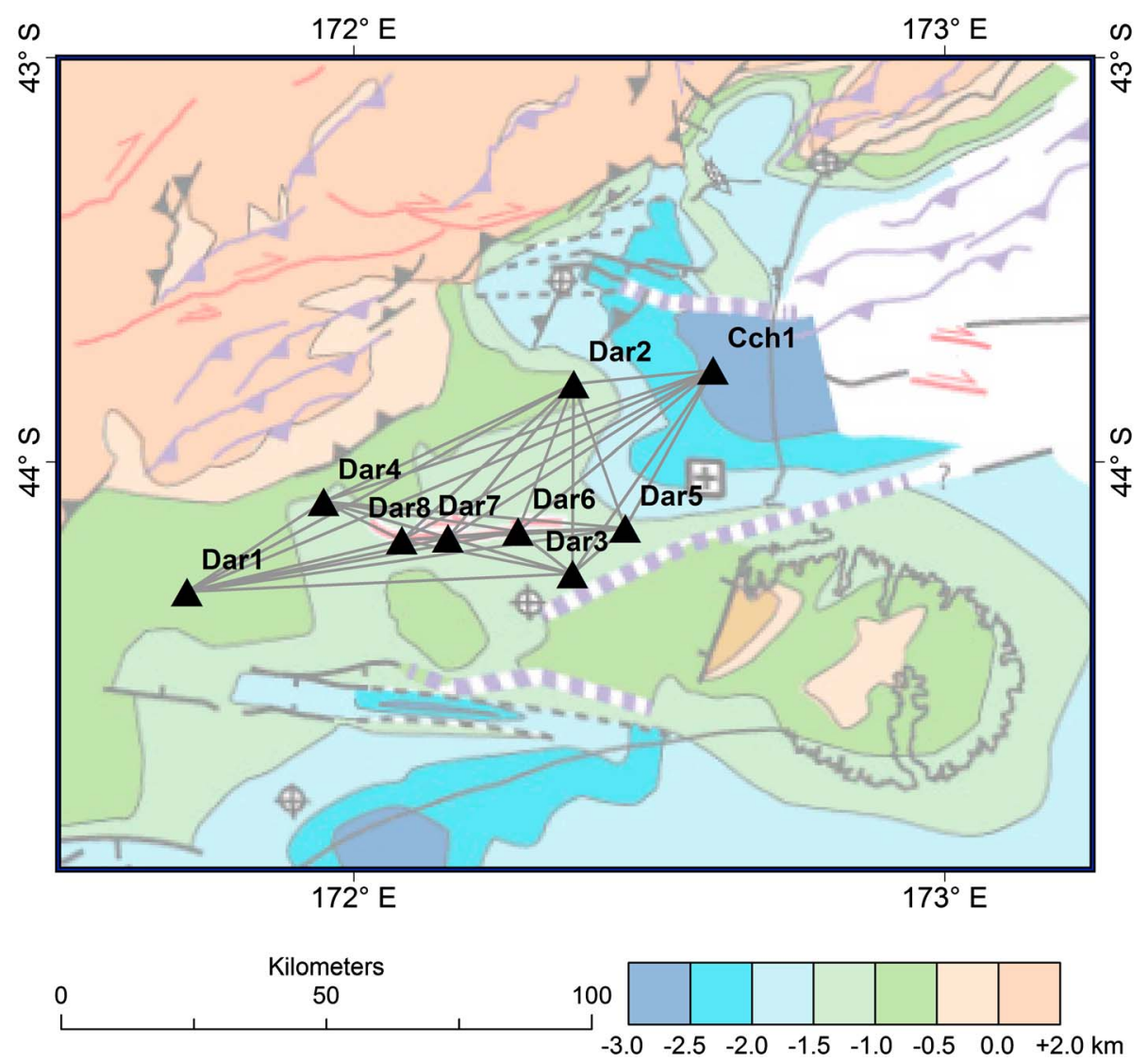

Figure 1. Location map with the seismographs used in this study (black triangles), inter-seismograph paths (gray lines), faults and basement depths (color version from F. Ghisetti, personal communication, 2012 [after Ghisetti and Sibson, 2012]). Thick gray line outlines the shoreline.

[7] The Darfield earthquake occurred in the middle of the Canterbury Plains, where low-velocity sediments up to several kilometers thick overlie higher-velocity bedrock [Forsyth et al., 2008]. We present the cross-correlation results for 104 days on the intermediate-period stations, which all had the same Trillium 4 sensors supplied by IRIS/PASSCAL. The top of the basement lies approximately $0.5-1.5 \mathrm{~km}$ beneath most of the stations analyzed [Ghisetti and Sibson, 2012] (Figure 1).

\section{Method}

[8] Three-component noise records were processed using the method of Durand et al. [2011]. We resampled the original $100 \mathrm{~Hz}$ data at $25 \mathrm{~Hz}$ and processed it in $2 \mathrm{~h}$ segments. The mean and trend were removed, then amplitudes larger than three times the root mean square (RMS) values were clipped. The data were whitened from 0.02 to $12 \mathrm{~Hz}$, and one-bit normalization was applied to remove earthquake signals dominating the correlations [Bensen et al., 2007]. For each segment, each of the three components at one station was cross-correlated with each component at every other station (with a maximum time lag of $340 \mathrm{~s}$ ). This yielded nine cross-correlograms: ZZ, ZR, ZT, RZ, RR, $\mathrm{RT}, \mathrm{TZ}, \mathrm{TR}$, and TT, where R, T, and $\mathrm{Z}$ stand for the radial, transverse, and vertical components, respectively, determined from the station-pair geometry. Mean crosscorrelograms were calculated from every 12 successive $2 \mathrm{~h}$ segments, yielding a daily cross-correlogram for each of the
104 days on which data were available from all stations. Those daily files were stacked to create final station-station cross-correlograms.

[9] For a diffuse equipartitioned noise field, the nine cross correlations between pairs of seismograph components can be directly related to the nine-component Green's functions [Lobkis and Weaver, 2001; Snieder, 2004; Tsai, 2010]. For positive time lags, the first letter can be interpreted as the direction of a point force source, and the second letter as the receiver response in that direction. For example, the ZR component gives the response to a point force in the $Z$ direction at the first station recorded on the $\mathrm{R}$ component at the second station. Negative time-lag signals reverse the roles of source and receiver at the first and second stations. Based on reciprocity, symmetric components of cross-correlation functions are calculated by time reversing the negative lag signal and summing it with the positive one.

\section{Results}

[10] Figure 2 shows the nine cross-correlograms obtained for a representative station pair (Dar2 and Dar3). Only the TT component exhibits high energy propagating in both directions, suggesting a more diffuse source of noise than for the other components; this inference is consistent with other observations in NZ [Behr et al., 2013]. The other components exhibit distinctive differences in amplitude for positive and negative lags, and thus for waves propagating in opposite directions. For example, surface waves traveling 


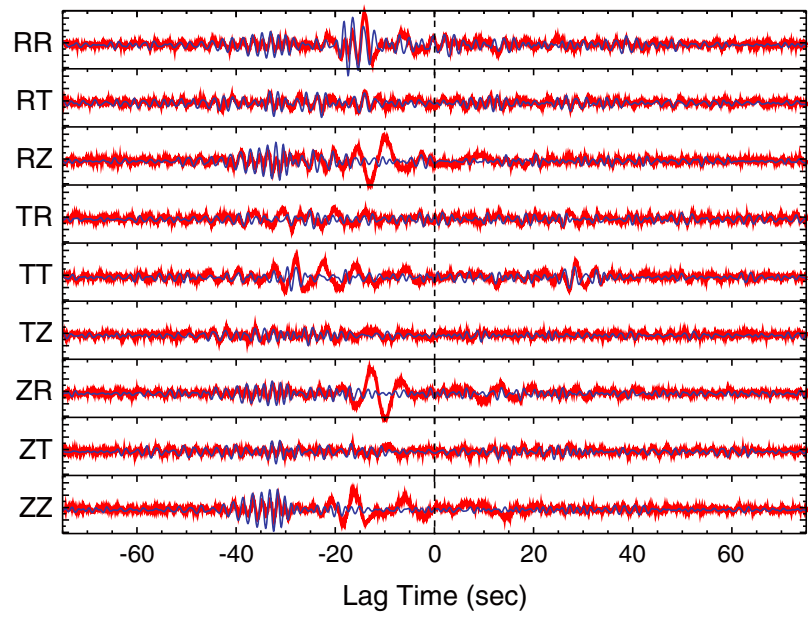

Figure 2. A representative example of the nine crosscorrelograms (R: radial; $\mathrm{T}$ : transverse; $\mathrm{Z}$ : vertical) obtained between stations Dar2 and Dar3 (Figure 1). The red and blue waveforms are broadband and $0.4-1 \mathrm{~Hz}$ band-pass-filtered cross-correlograms, respectively. Negative lag times represent waves traveling from Dar3 to Dar 2 (south to north); positive lag times represent waves traveling from Dar 2 to Dar 3 (north to south). Amplitudes of all nine cross-correlograms are normalized together based on the maximum amplitude of all components between -70 and $70 \mathrm{~s}$ time lag.

northward from Dar3 to Dar2 exhibit higher energies for most components and in most frequency bands than those traveling southward (Figure 2). Long-period energy in the $\mathrm{RZ}, \mathrm{ZR}$, and ZZ components arrives earlier than short-period energy, whereas for the RR and TT components, there is little obvious dispersion. For Rayleigh waves, there is no phase shift expected between $\mathrm{ZZ}$ and RR cross correlations, because both the receiver and the virtual source have the same $90^{\circ}$ phase shift, which cancels. However, a $180^{\circ}$ phase shift occurs between ZR and RZ components due to the $90^{\circ}$ phase with opposite sign at the receiver and the virtual source [e.g., Harkrider, 1964; Lin et al., 2008].

[11] High-frequency record sections were obtained by applying a two-pole, 0.4-1 Hz Butterworth filter (Figure 3). The clearest signals are seen for the RR component. Two main groups of arrivals can be differentiated at distances greater than $\sim 20 \mathrm{~km}$. The first signal arrives with a group velocity of $\sim 2 \mathrm{~km} / \mathrm{s}$ whereas energy corresponding to the second signal arrives later, at a time equivalent to a group velocity of $1 \mathrm{~km} / \mathrm{s}$. There is also some energy at the same times on the RZ component, but the TT component is indistinct between $1 \mathrm{~km} / \mathrm{s}$ and $2 \mathrm{~km} / \mathrm{s}$, and there is little energy on the $\mathrm{ZZ}$ component at these frequencies until later in the record.

[12] The supporting information (Figure S1) includes record sections of the broadband waveforms for all cross-correlation pairs for both positive and negative lags. Long-period $(>2.5 \mathrm{~s})$ energy is present in most components, arriving at speeds greater than $2 \mathrm{~km} / \mathrm{s}$. It is particularly simple and prominent on the TT component, appearing as a long, dispersed wave train. The other components suggest two packets of energy, with long periods $(>2.5 \mathrm{~s})$ arriving early and shorter periods (1-2.5 s) later. Shorter periods predominantly arrive from the east.

\section{Discussion}

[13] The cross-correlograms are compared with synthetic waveforms calculated using the normal mode summation module of "Computer Programs in Seismology" [Herrmann and Ammon, 2002] (http://www.eas.slu.edu/eqc/eqccps.html) (Figure 3). We use single-force point sources located at $0.75 \mathrm{~km}$ depth in a model consisting of a $1.5 \mathrm{~km}$ upper layer with a $P$ wave velocity of $2.4 \mathrm{~km} / \mathrm{s}, S$ wave velocity of $1.3 \mathrm{~km} / \mathrm{s}$ and density of $1.41 \mathrm{Mg} / \mathrm{m}^{3}$ overlying a half space with $P$ wave velocity of $5.4 \mathrm{~km} / \mathrm{s}, S$ velocity of $3.0 \mathrm{~km} / \mathrm{s}$ and density of $2.7 \mathrm{Mg} / \mathrm{m}^{3}$. This model is a simplification of the Canterbury Basin portion of the velocity model used by Guidotti et al. [2011] to model strong-motion records from the Darfield and the 22 February 2011 Christchurch earthquakes. Guidotti et al. [2011] based the model on structural maps of the Canterbury Basin and sediment velocities from geotechnical studies in other regions of New Zealand.

[14] Based on the synthetic seismograms, we conclude that the early-arriving signal we see in the RR cross-correlogram
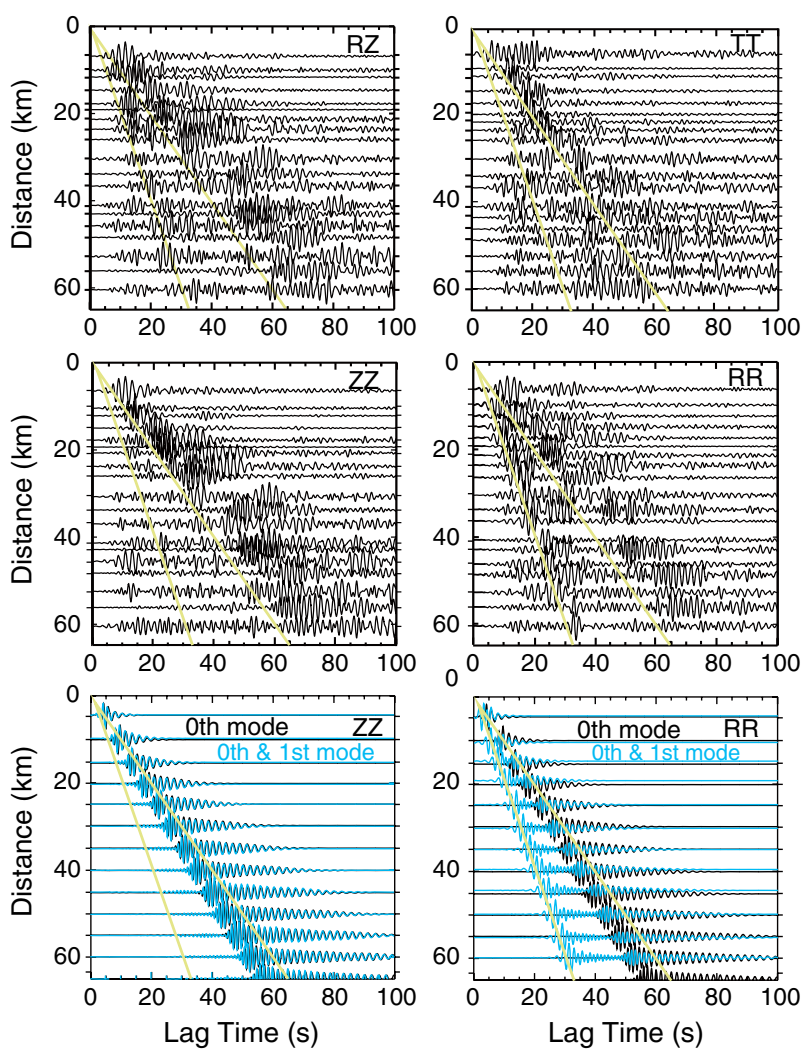

Figure 3. Record sections. Top four plots are the RZ, TT, $\mathrm{ZZ}$, and RR component symmetric cross correlations of real data band-passed from 0.4 to $1 \mathrm{~Hz}$. To minimize overlapping traces, representative station pairs were chosen among those that are close in distance. The full data set is plotted in the supporting information (Figure S1). The bottom two plots are synthetic seismograms of the fundamental (black) and the fundamental + first higher-mode waves (cyan). The yellow lines denote 1 and $2 \mathrm{~km} / \mathrm{s}$ moveout speed. Each waveform is normalized relative to its own maximum amplitude. The synthetic ZZ components look nearly identical for the fundamental and first-higher mode, while the synthetic RR components have early arrivals when the first-higher mode is included. 

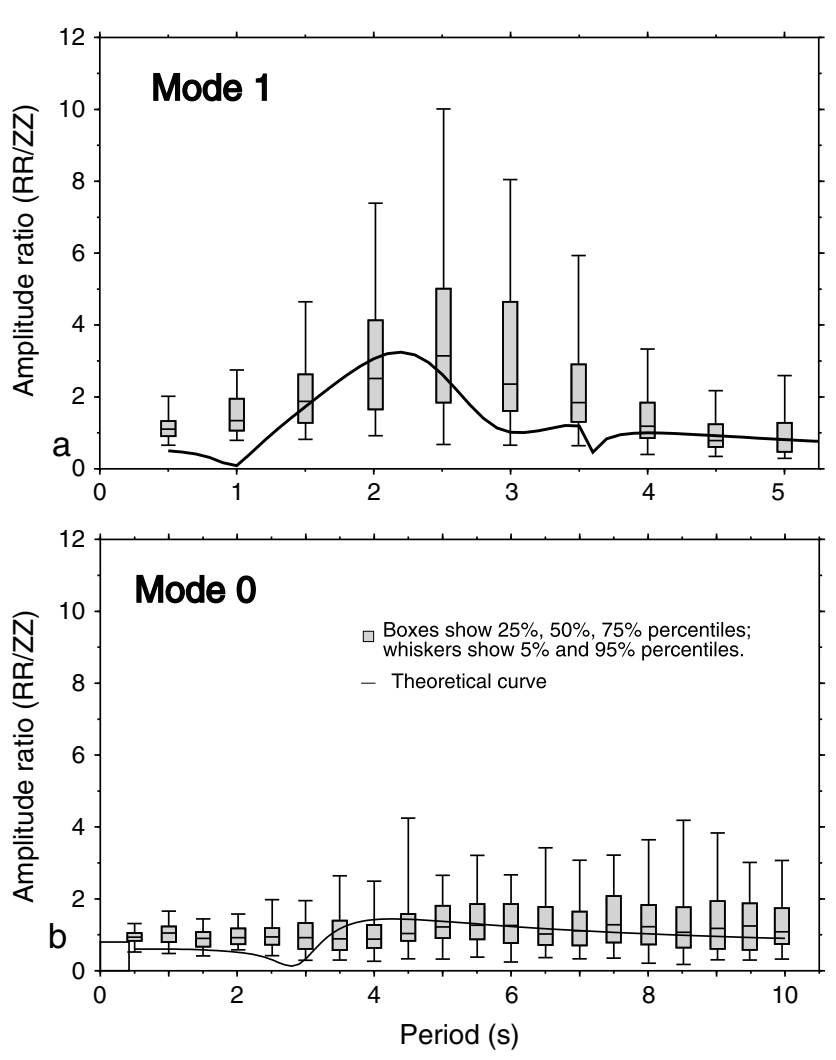

Figure 4. Absolute value of $\mathrm{H} / \mathrm{V}$ ratios from synthetic modeling (curve), and the observed distributions over all station pairs of the maximum amplitude of the radial component divided by the maximum amplitude of the vertical component for the given mode (see text for definition). Box and whiskers plots are shown from the entire distribution. For separation into westward- and eastward-propagating paths, see Figure S3. (a) Mode 1; (b) Mode 0. Note the change of scale for the period axis, since the first-order mode had smaller window lengths than that of the fundamental mode.

is likely the first higher mode of the Rayleigh wave. The phase is present when both the fundamental mode and first higher mode are included in the synthetic calculations, but not when only the fundamental mode is included (Figure 3). Both the data and the synthetics for the first higher mode have very little energy on the vertical component, which makes them appear to be longitudinal waves (Figure 3 and Movie $\mathrm{S} 5$ of the supporting information). Although $P$ waves are also longitudinal, these are Rayleigh waves and are most sensitive to the $S$ velocity (Figure S2). The arrival times are similar for the synthetics and observations for the first higher mode ( $\sim 20 \mathrm{~s}$ at $39 \mathrm{~km}$ distance) and somewhat different for the fundamental mode $(\sim 35 \mathrm{~s}$ and $\sim 40 \mathrm{~s}$ at $39 \mathrm{~km}$ distance for the synthetics and observations, respectively).

[15] We calculate the horizontal to vertical (H/V) Rayleigh wave amplitude ratio for each period using the maximum amplitudes of the RR divided by the $\mathrm{ZZ}$ cross-correlograms in the time windows that best separate the two modes. Theoretically, the H/V ratio should be determined based on radial and vertical Rayleigh wave amplitudes excited by a common source (such as an earthquake [Lin et al., 2012]). However, in this study, the exact amplitude information of the Rayleigh waves is likely lost due to one-bit normalization and spectrum whitening. A more sophisticated analysis is required to retain true amplitude information from noise cross-correlation results [Lin et al., 2011; Tsai, 2011; Weaver, 2011] and is beyond the scope of this study. Nevertheless, some studies suggest that one-bit noise cross correlations retain their relative amplitudes [Cupillard et al., 2011]. Since the same analysis has been applied to both components, we consider our approach to be suitable for the purposes of studying $\mathrm{H} / \mathrm{V}$ ratio as a function of period.

[16] The two dominant packets of energy are distinguished based on wave speed in the $0.4-1.0 \mathrm{~Hz}$ frequency band, from a visual inspection of the arrival times of the wave packets (Figure 3). Let $x$ be the distance (in kilometers) between station pairs. The first higher mode (mode 1) is the part of the signal that begins at the time (in seconds) given by $x / 6.0$, and ends at $x / 1.1$. In other words, energy arriving with velocities between 1.1 and $6.0 \mathrm{~km} / \mathrm{s}$ is treated as mode 1. The lengths of the windows vary between $4.7 \mathrm{~s}$ for stations Dar7 and Dar8, which are $6.3 \mathrm{~km}$ apart, and $57.9 \mathrm{~s}$ for stations Cch1 and Dar1, which are $78 \mathrm{~km}$ apart. The fundamental mode (mode 0 ) is considered to be the part of the signal that arrives between $x / 1.1$ and either $x / 0.25$ or $100 \mathrm{~s}$, whichever is smaller. The maximum window length ensures that distant station pairs do not contain long noise trains. The separation is best at distances greater than $15 \mathrm{~km}$ (Figures 3 and S1). These are approximations because branch crossings [Boaga et al., 2013] cause some long-period energy from mode 0 to contaminate mode 1 .

[17] For signal-to-noise (SNR) calculations, the noise was estimated from $150 \mathrm{~s}$ windows at the beginning and end of the cross correlogram. For each period, the maximum amplitude within the positive or negative lag signal window was divided by the RMS amplitude in the corresponding positive or negative noise window to calculate the SNR.

[18] The horizontal to vertical ratio ( $\mathrm{H} / \mathrm{V}$ ratio) of mode 1 is predicted to be peaked at a period of $\sim 2 \mathrm{~s}$, with an $\mathrm{H} / \mathrm{V}$ ratio of $\sim 3$, based on numerical calculations using the assumed regional velocity model (Figure 4) [Herrmann and Ammon, 2002, Table 1]. This period corresponds to the resonance frequency of the 1-D structure and is mainly controlled

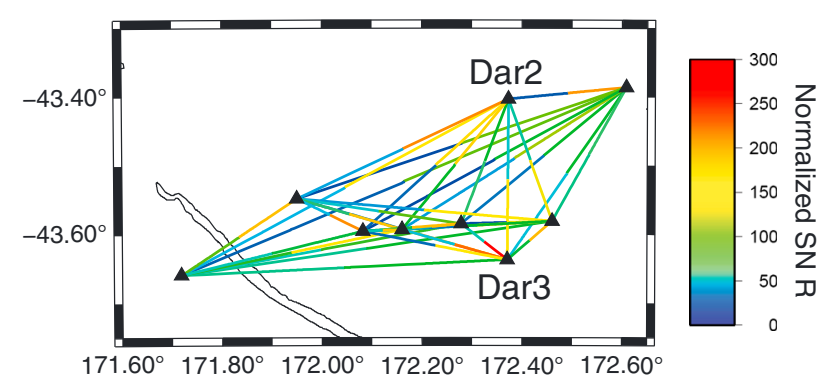

Figure 5. Summary of ambient noise directionality for the first higher-mode energy between 0.4 and $1 \mathrm{~Hz}$. The line connecting each station pair is colored by the normalized SNR of the energy emanating from the station, in which the SNR is multiplied by the square root of the interstation distance. For example, the path between Dar2 and Dar3 of Figure 2 has a high value (yellow color) for the northward energy propagating from the south at station Dar3 (negative time lag in Figure 2) and low energy (blue color) for the southward propagating energy from station Dar2 (positive time lag in Figure 2). 
by the velocity and thickness of the sedimentary layer above the bed rock [Fäh et al., 2001]. Comparison of H/V in the data confirms a strong peak at $2.5 \mathrm{~s}$ for mode 1 , with more subtle behavior for mode 0 (Figure 4). The peak for mode 1 is present for propagation in all directions, but is strongest for westward propagation (Figure S3). There is large scatter, as is common in amplitude studies [e.g.,Romanowicz, 1998]. Because amplitudes of the first higher mode are too small to be measured on the $\mathrm{ZZ}$ component (Figure 3), we consider our estimated $\mathrm{H} / \mathrm{V}$ ratio to be a lower bound.

[19] Other groups have reported amplification at periods of $\sim 2.5 \mathrm{~s}$ (frequencies of $\sim 0.4 \mathrm{~Hz}$ ) in the Canterbury region. Guidotti et al. [2011] determined spectral peaks at $0.4 \mathrm{~Hz}$ for the Darfield and Christchurch earthquakes recorded on strong-motion sites but did not discuss ratios of components. Mucciarelli [2011] measured single-station H/V noise spectral ratios in the Christchurch area, concentrating on high frequencies. There were four sites in which the highest peaks were observed at frequencies $\leq 0.5 \mathrm{~Hz}$, and those averaged $0.41 \mathrm{~Hz}$ with spectral ratio amplitudes of 2.7 , similar to our results. Other sites, particularly in the western regions, also exhibited small $\mathrm{H} / \mathrm{V}$ ratio peaks at $\sim 0.5 \mathrm{~Hz}$, but these were usually smaller than the higher-frequency peaks. Using standard geotechnical methods, [Toshinawa et al., 1997] also reported some dominant periods and $\mathrm{H} / \mathrm{V}$ spectral peaks of $\sim 0.5 \mathrm{~s}$ in the Christchurch region.

[20] Mode 1 is sensitive to both shallower and deeper structure than the fundamental mode (Figure S2). Using both modes will help to better model the structure of basins.

[21] We attribute the asymmetry in the amplitudes of positive and negative arrivals in Figures 2, 4, and S1 to the proximity of our array to the coast (Figure 1). Ocean waves arriving at the coast will preferentially propagate energy from the east (and from the South in the case of Dar3 to Dar2) [Behr et al., 2013; Lin et al., 2007]. SNR for the radial component of the first higher mode are almost always higher for paths traveling away from the coast (generally from east to west) than for those traveling in the opposite direction (Figure 5). Figure S4 further explores the amplification for the fundamental and first modes.

\section{Conclusions}

[22] In the Canterbury Plains, New Zealand, and in general for low-velocity sedimentary basins, Rayleigh wave higher modes are dominant in the horizontal plane, and at a resonance frequency for the upper crustal layer. Such resonance could cause damaging effects for structures that resonate at the same periods. We suggest that the current practice of examining only the dominant normal mode for noise analysis be extended to include multiple components and higher modes.

[23] The strong directionality of the higher-mode amplitudes suggests that this mode is created by waves approaching or breaking at the shoreline. If so, then we expect that such modes should be observed in other basins near coasts, such as the Los Angeles basin [Lin et al., 2013], although the specific resonance frequency and $H / V$ ratio will depend on detailed sedimentary structure.

[24] Acknowledgments. This work was funded by grants from the New Zealand Earthquake Commission, the New Zealand Marsden Fund U.S. National Science Foundation, and GNS Science. F. Lin was supported by the Director's Post-Doctoral Fellowship of the Seismological Laboratory at the California Institute of Technology and NSF grant EAR-1252191. GNS Science Wairakei, University of Auckland and PASSCAL RAMP provided instrumentation. M. Henderson, K. Allan, A. Zaino, J. Eccles, K. Jacobs, C. Boese, R. Davy, A. Wech, N. Lord, and A. Carrizales helped in the field and with organizing the data. Z. Rawlinson, P. Malin, and B. Fry helped plan station locations. F. Brenguier provided cross-correlation codes. Y. Behr and C. Juretzek provided further codes and initial analysis of vertical-component seismograms. C. Thurber and E. Syracuse helped plan and carry out the deployment. F. Ghisetti and R. Sibson provided the color version of their basement depth map used as a background in Figure 1.

[25] The Editor thanks two anonymous reviewers for their assistance in evaluating this paper.

\section{References}

Behr, Y. (2011), Imaging New Zealand's Crustal Structure Using Ambient Seismic Noise Recordings from Permanent and Temporary Instruments, $196 \mathrm{pp}$, Victoria Univ. of Wellington, Wellington.

Behr, Y., J. Townend, M. Bowen, L. Carter, R. Gorman, L. Brooks, and S. Bannister (2013), Source directionality of ambient seismic noise inferred from three-component beamforming, J. Geophys. Res. Solid Earth, 118, 240-248, doi:10.1029/2012JB009382.

Bensen, G. D., M. H. Ritzwoller, M. P. Barmin, A. L. Levshin, F. C. Lin, M. P. Moschetti, N. M. Shapiro, and Y. Yang (2007), Processing seismic ambient noise data to obtain reliable broad-band surface wave dispersion measurements, Geophys. J. Int., 169, 1239-1260, doi:10.1111/ j.1365-246X.2007.03374.x.

Boaga, J., G. Cassiani, C. L. Strobbia, and G. Vignoli (2013), Mode misidentification in Rayleigh waves: Ellipticity as a cause and a cure, Geophysics, 78(4), 1-12, doi:10.1190/GEO2012-0194.1.

Bonnefoy-Claudet, S., F. Cotton, and P. Y. Bard (2006), The nature of noise wavefield and its applications for site effects studies, A literature review, Earth Sci. Rev., 79(3-4), 205-227, doi:10.1016/j.earscirev.2006.07.004.

Boore, D. M., and M. N. Toksoz (1969), Rayleigh wave particle motion and crustal structure, Bull. Seismol. Soc. Am., 59(1), 331-346.

Brooks, L. A., J. Townend, P. Gerstoft, S. Bannister, and L. Carter (2009), Fundamental and higher-mode Rayleigh wave characteristics of ambient seismic noise in New Zealand, Geophys. Res. Lett., 36, L23303, doi:10.1029/2009GL040434.

Cupillard, P., L. Stehly, and B. Romanowicz (2011), The one-bit noise correlation: A theory based on the concepts of coherent and incoherent noise, Geophys. J. Int., 184, 1397-1414, doi:10.1111/ j.1365-246X.2010.04923.x.

Durand, S., J. P. Montagner, P. Roux, F. Brenguier, R. M. Nadeau, and Y. Ricard (2011), Passive monitoring of anisotropy change associated with the Parkfield 2004 earthquake, Geophys. Res. Lett., 38, L13303, doi:10.1029/2011 gl047875.

Fäh, D., F. Kind, and D. Giardini (2001), A theoretical investigation of average H/V ratios, Geophys. J. Int., 145(2), 535-549, doi:10.1046/ j.0956-540X.2001.01406.x.

Forsyth, P. J., D. J. A. Barrell, and R. Jongens (2008), Geology of the Christchurch Area, 1:250,000 Geological Map 16, GNS Sci., Lower Hutt, New Zealand.

Ghisetti, F. C., and R. H. Sibson (2012), Compressional reactivation of E-W inherited normal faults in the area of the 2010-2011 Canterbury earthquake sequence, N. Z. J. Geol. Geophys., 55(3), 177-184, doi:10.1080/ 00288306.2012 .674048 .

Gledhill, K., J. Ristau, M. Reyners, B. Fry, and C. Holden (2011), The Darfield (Canterbury, New Zealand) MW 7.1 earthquake of September 2010: A preliminary seismological report, Seismol. Res. Lett., 82, 379-386.

Guidotti, R., M. Stupazzini, C. Smerzini, R. Paolucci, and P. Ramieri (2011), Numerical study on the role of basin geometry and kinematic seismic source in 3D ground motion simulation of the 22 February $2011 \mathrm{Mw}$ 6.2 Christchurch earthquake, Seismol. Res. Lett., 82(6), 767-782.

Harkrider, D. G. (1964), Surface waves in multilayered elastic media I. Rayleigh and Love waves from buried sources in a multilayered elastic half-space, Bull. Seismol. Soc. Am., 54(2), 627-679.

Harmon, N., D. Forsyth, and S. Webb (2007), Using ambient seismic noise to determine short-period phase velocities and shallow shear velocities in young oceanic lithosphere, Bull. Seismol. Soc. Am., 97(6), 2009-2023, doi:10.1785/0120070050.

Herrmann, R. B., and C. J. Ammon (2002), Computer Programs in Seismology: Surface Waves, Receiver Functions and Crustal Structure, St. Louis Univ., St. Louis, Mo.

Kimman, W. P., X. Campman, and J. Trampert (2012), Characteristics of seismic noise: Fundamental and higher mode energy observed in the northeast of the Netherlands, Bull. Seismol. Soc. Am., 102(4), 1388-1399, doi: $10.1785 / 0120110069$.

Lin, F. C., M. H. Ritzwoller, J. Townend, S. Bannister, and M. K. Savage (2007), Ambient noise Rayleigh wave tomography 
of New Zealand, Geophys. J. Int., 170(2), 649-666, doi:10.1111/ j.1365-246X.2007.03414.x.

Lin, F. C., M. P. Moschetti, and M. H. Ritzwoller (2008), Surface wave tomography of the western United States from ambient seismic noise: Rayleigh and Love wave phase velocity maps, Geophys. J. Int., 173(1), 281-298, doi:10.1111/j.1365-246X.2008.03720.x.

Lin, F. C., M. H. Ritzwoller, and W. Shen (2011), On the reliability of attenuation measurements from ambient noise cross-correlations, Geophys. Res. Lett., 38, L11303, doi:10.1029/2011g1047366.

Lin, F. C., B. Schmandt, and V. C. Tsai (2012), Joint inversion of Rayleigh wave phase velocity and ellipticity using USArray: Constraining velocity and density structure in the upper crust, Geophys. Res. Lett., 39, L12303, doi:10.1029/2012g1052196.

Lin, F. C., D. Li, R. W. Clayton, and D. Hollis (2013), High-resolution 3D shallow crustal structure in Long Beach, California: Application of ambient noise tomography on a dense seismic array, Geophysics, doi:10.1190/GEO2012-0453.1, in press.

Lobkis, O. I., and R. L. Weaver (2001), On the emergence of the Green's function in the correlations of a diffuse field, J. Acoust. Soc. Am., 110(6), 3011-3017, doi:10.1121/1.1417528.

Louie, J. N. (2001), Faster, better: Shear-wave velocity to 100 meters depth from refraction microtremor arrays, Bull. Seismol. Soc. Am., 91(2), 347-364, doi:10.1785/0120000098.

Moschetti, M. P., M. H. Ritzwoller, F. C. Lin, and Y. Yang (2010), Crustal shear wave velocity structure of the western United States inferred from ambient seismic noise and earthquake data, J. Geophys. Res., 115, B10306, doi:10.1029/2010jb007448.

Mucciarelli, M. (2011), Ambient noise measurements following the 2011 Christchurch earthquake: Relationships with previous microzonation studies, liquefaction, and nonlinearity, Seismol. Res. Lett., 82(6), 919-926.

Nakamura, Y. (1989), A method for dynamic characteristics estimation of subsurface using microtremor on the ground surface, $Q$. Rep. Railways Technol. Res. Inst., 30, 25-30.
Quigley, M., et al. (2010), Surface rupture of the Greendale Fault during the Darfield (Canterbury) earthquake, New Zealand: Initial findings, Bull. N. Z. Soc. Earthquake Eng., 43(4), 236-242.

Romanowicz, B. (1998), Attenuation tomography of the Earth's mantle: A review of current status, Pure Appl. Geophys., 153, 257-272.

Sabra, K. G., P. Gerstoft, P. Roux, W. A. Kuperman, and M. C. Fehler (2005), Extracting time-domain Green's function estimates from ambient seismic noise, Geophys. Res. Lett., 32, L03310, doi:10.1029/2004g1021862.

Shapiro, N. M., and M. Campillo (2004), Emergence of broadband Rayleigh waves from correlations of the ambient seismic noise, Geophys. Res. Lett., 31, L07614, doi:10.1029/2004GL019491.

Snieder, R. (2004), Extracting the Green's function from the correlation of coda waves: A derivation based on stationary phase, Phys. Rev. E., 69(4 2), 1-8, doi:10.1103/PhysRevE.69.046610.

Syracuse, E., R. Holt, M. Savage, J. Johnson, C. Thurber, K. Unglert, K. Allan, S. Karaliyadda, and M. Henderson (2012), Temporal and spatial evolution of hypocentres and anisotropy from the Darfield aftershock sequence: Implications for fault geometry and age, N. Z. J. Geol. Geophys., doi:10.1080/00288306.2012.690766.

Toshinawa, T., J. J. Taber, and J. B. Berrill (1997), Distribution of groundmotion intensity inferred from questionnaire survey, earthquake recordings, and microtremor measurements - A case study in Christchurch, New Zealand, during the 1994 Arthurs Pass earthquake, Bull. Seismol. Soc. Am., 87(2), 356-369.

Tsai, V. C. (2010), The relationship between noise correlation and the Green's function in the presence of degeneracy and the absence of equipartition, Geophys. J. Int., 182(3), 1509-1514, doi:10.1111/j.1365246X.2010.04693.x.

Tsai, V. C. (2011), Understanding the amplitudes of noise correlation measurements, J. Geophys. Res., 116, B09311, doi:10.1029/2011jb008483.

Weaver, R. L. (2011), On the amplitudes of correlations and the inference of attenuations, specific intensities and site factors from ambient noise, $C . R$. Geosci., 343(8-9), 615-622, doi:10.1016/j.crte.2011.07.001. 
SAVAGE ET AL.: HIGHER-MODE RAYLEIGH WAVES AND RESONANCE

\section{Erratum}

In the originally published version of this manuscript, Table 1 was missing. Table 1 has since been added, and this version may be considered the authoritative version of record.

Table 1. Synthetic Velocity Model

\begin{tabular}{lcccc}
\hline Layer number & Thickness $(\mathrm{km})$ & $S$ Wave Velocity $\left(V_{\mathrm{s}}, \mathrm{km} / \mathrm{s}\right)$ & $P$ Wave Velocity $\left(V_{\mathrm{p}}, \mathrm{km} / \mathrm{s}\right)$ & Density $\left(\mathrm{Mg} / \mathrm{m}^{3}\right)$ \\
\hline 1 & 1.5 & 1.3 & 2.4 & 1.41 \\
2 & Infinite & 3.0 & 5.4 & 2.7 \\
\hline
\end{tabular}

